\title{
Virtual Peer Teaching During the COVID-19 Pandemic
}

\section{Lily Jeong $^{1} \cdot$ Zachary Smith $^{1} \cdot$ August Longino $^{1} \cdot$ Susan E. Merel ${ }^{2} \cdot$ Karen McDonough $^{2}$ (I)}

Published online: 9 September 2020

(C) International Association of Medical Science Educators 2020

\begin{abstract}
Virtual peer teaching can be part of the solution to challenges in medical education during the pandemic. We developed an online clinician teacher elective, implemented virtual peer teaching throughout our curriculum, and believe it benefits students, peer teachers, and faculty. We plan to continue virtual peer teaching beyond the pandemic.
\end{abstract}

Keywords Online education $\cdot$ Peer teaching $\cdot$ Clinical skills education

The COVID-19 pandemic has disrupted medical education across the world [1]. Teaching has quickly transitioned from in-person to online, and clerkship students who have been removed from clinical rotations are seeking other ways to contribute. For many clinicians, increased patient care demands have limited the time available for teaching. At the University of Washington School of Medicine, virtual peer teaching — students teaching students via videoconferencehas helped us meet these educational challenges and shows promise for use beyond the pandemic.

As the pandemic started, we recognized several potential benefits of virtual peer teaching. Studies of in-person medical school peer teaching have shown similar performance for learners taught by faculty instructors and those taught by fellow students [2]. Peer teachers would be more available than faculty to facilitate the new problem-based online sessions that replaced some clinical activities. Adding more online small group leaders would allow a lower student-to-teacher ratio and more interaction. Teaching could be a worthwhile experience for students sidelined from clinical rotations. Peer teaching builds teaching and leadership skills in the instructor and can also lead to a better understanding of the subject matter being taught [3].

\section{Karen McDonough}

kmcdonou@uw.edu

1 University of Washington School of Medicine, Seattle, WA, USA

2 Division of General Internal Medicine, Department of Medicine, University of Washington, Seattle, WA, USA
We initially recruited volunteers, and then quickly developed an online credit-bearing clinician educator elective (Table 1). In interactive online didactics, faculty teach key skills such as small group facilitation, teaching scripts, and feedback. Participants practice using these skills in course activities, as well as in basic science and clinical skills small groups. They are observed by and receive feedback from other peer teachers and reflect on their experience and goals weekly. Fourteen percent of third and fourth year students have joined our virtual peer teacher elective and are teaching medical students at all levels across our six regional campuses.

Early, informal feedback has been positive. Videoconference technology has allowed students to easily connect across campuses, building community in a difficult time. Peer teachers have found it easy to participate in both didactic sessions and teaching. Their involvement has helped us to achieve clinical skills, basic science, and clerkship goals and objectives despite the rapid shift to online teaching. First year students appreciate the mentorship and connection with senior students.

The effectiveness of both peer teaching and interactive virtual learning in health sciences education is well established [2-4]. Our experiment with virtual peer teaching, born of necessity, has led to three key insights.

First, teaching has been a meaningful way for medical students to contribute during this crisis. Medical students' involvement with patient care has been limited, and they have found creative and inspiring ways to make a difference. Peer teachers support the education of future physicians as current physicians care for patients. Thirty-two peer teachers who completed an anonymous survey agreed that the experience benefited their medical education and preparation for 
Table 1 Peer teaching activities and learners

\begin{tabular}{|c|c|c|c|c|}
\hline Online activity & Purpose & Learners & Role of virtual peer teachers & $\begin{array}{l}\text { Learner } \\
\text { contact- } \\
\text { hours in } \\
8 \text { weeks }\end{array}$ \\
\hline Primary care case discussions & $\begin{array}{l}\text { New sessions replacing a clinical } \\
\text { experience }\end{array}$ & MS1 & $\begin{array}{l}\text { Small group facilitator } \\
\text { Observe and provide feedback to } \\
\text { another peer teacher }\end{array}$ & 13,500 \\
\hline $\begin{array}{l}\text { Musculoskeletal case } \\
\text { discussions }\end{array}$ & $\begin{array}{l}\text { Converted from in-person to virtual } \\
\text { small group }\end{array}$ & MS1 & Small group facilitator & 400 \\
\hline Clinical skills groups & $\begin{array}{l}\text { Converted from in-person to virtual small } \\
\text { group }\end{array}$ & MS1 & $\begin{array}{l}\text { Act as a virtual standardized patient } \\
\text { Provide feedback to learners on } \\
\text { communication skills }\end{array}$ & 400 \\
\hline Student report & $\begin{array}{l}\text { For students who have not been able } \\
\text { to start clerkships }\end{array}$ & MS2 & $\begin{array}{l}\text { Prepare a patient case } \\
\text { Facilitate videoconference case discussion }\end{array}$ & 320 \\
\hline Virtual medicine subinternship & $\begin{array}{l}\text { Part of a month-long online course } \\
\text { replacing the subinternship }\end{array}$ & MS4 & $\begin{array}{l}\text { Prepare and deliver case-based sessions } \\
\text { Help plan course and recruit faculty } \\
\text { teachers }\end{array}$ & 1560 \\
\hline
\end{tabular}

residency, and all would recommend the experience to a classmate. Twenty-nine of 32 agreed or strongly agreed that virtual small groups are an effective learning modality.

Second, an accessible teaching elective can be delivered virtually. We found that core material can be presented in online didactics, participants can practice some skills in virtual breakout rooms, and relevant teaching experience can be gained via videoconference. Future iterations of the elective will likely be a hybrid of online didactic sessions accessible to clerkship students spread across five states and a mix of online and in-person teaching experience, coupled with observation and coaching.

Third, technology makes peer teaching much more feasible. At the start of the pandemic, all students and faculty were assigned individual videoconference accounts, allowing sessions to occur at flexible times. As one example, first year students across our six regional campuses in three different time zones attended a series of five peer-led case-based small groups. Peer teachers chose times convenient for them. Learners chose their time slots using a commercially available online sign-up program and each teacher scheduled their own videoconference and shared the link with their group. Teaching guides were posted on a shared drive, and facilitator prep sessions occurred online. This crisis showed us that available technology can overcome the three factors that had previously limited our use of peer teaching: conflicting schedules, administrative burden, and physical distance.

Virtual peer teaching is a supplemental learning medium that is flexible and adaptable to any learning environment with internet access. It has the potential to support learning while fostering a sense of community even after physical distancing is no longer necessary, allowing senior students to develop teaching and mentorship skills while providing junior students with a welcoming learning environment that facilitates curiosity and exploration.

\section{Compliance with Ethical Standards}

Conflict of Interest The authors declare that they have no conflict of interest.

Ethical Approval N/A

Informed Consent N/A

\section{References}

1. Soled D, Goel S, Barry D, Erfani P, Joseph N, Kochis M, et al. Medical student mobilization during a crisis. In: Lessons from a COVID-19 medical student response team Acad Med; 2020, April 8. Published online ahead of print. https://doi.org/10.1097/ ACM0000000000003401.

2. Bene KL, Bergus G. When learners become teachers: a review of peer teaching in medical student education. Fam Med. 2014;46(10): 783-7.

3. Hall S, Harrison CH, Stephens J, Andrade MG, Seaby EG, Parton W, et al. The benefits of being a near-peer teacher. Clin Teach. 2018;15: 403-7.

4. George PP, Papachristou N, Belisario JM, Wang W, Wark PA, Cotic $\mathrm{Z}$, et al. Online eLearning for undergraduates in health professions: a systematic review of the impact on knowledge, skills, attitudes and satisfaction. J Glob Health. 2014;4(1):010406.

Publisher's Note Springer Nature remains neutral with regard to jurisdictional claims in published maps and institutional affiliations. 